\title{
Benzalkonium Chloride Sterilization of Nonwoven Fibrous Scaffolds for Astrocyte Culture
}

\author{
Robin $\mathrm{Ng}^{\#}$, Jesse Singh Gurm and Shang-Tian Yang* \\ William G. Lowrie Department of Chemical and Biomolecular Engineering, The Ohio State University, 140 West 19th \\ Avenue, Columbus OH 43210, USA
}

\begin{abstract}
Tissue engineering is an emerging field in biomedicine, holding enormous promise for regenerative medicine. Scaffolds, within which cells proliferate, are a controlling factor in tissue engineering applications. Upon fabrication, tissue scaffolds must undergo appropriate sterilization to eliminate contaminants. Current sterilization methods are either costly, time consuming, or ineffective. In this study, a quaternary salt, benzalkonium chloride (BAC), was used as a chemical agent for sterilization of nonwoven polyethylene terephthalate (PET) fibers and polylactic acid nanofibers. Treating the PET scaffolds with $0.1 \%$ (w/v) BAC for only 2 minutes was effective to eliminate bacterial contaminants in the fibrous matrices. In addition, astrocyte cells were successfully cultured in the PET scaffolds following BAC sterilization, demonstrating the suitability of BAC as a sterilization agent. This chemical sterilization method is also mild and nonabrasive to nanostructured materials such as electrospun polylactic acid nanofibers.
\end{abstract}

Keywords: Astrocyte, benzalkonium chloride, nanofiber, polyethylene terephthalate, polylactic acid, sterilization, tissue scaffold.

\section{INTRODUCTION}

In tissue engineering, scaffolding materials play a pivotal role and dictate the success of the system. Many polymeric materials, both nature and synthetic, have been used as tissue scaffolds in various tissue engineering applications [1]. Particularly, porous fibrous materials are widely used as support matrices and tissue scaffolds in cell cultures and tissue engineering [2-11]. Prior to use, the scaffolding materials must be properly sterilized to ensure the hygiene of the scaffold. Failure to removal of all contaminating microorganisms can impede the function of seeded cells and result in infections inside the patient body.

Several sterilization media are available for tissue engineering applications: dry heat, steam, gases, irradiation, and chemicals. In general, dry heat cannot penetrate porous scaffolds very effectively. On the other hand, steam has better heat penetration but can easily damage, destroy, or change the properties of the scaffolds, especially those made of biodegradable polymers, such as poly-lactic acid, and those with nanoscale structures, such as nanofibers. Gamma irradiation, which is used in sterilizing heat-sensitive materials in hospitals and the food industry, is relatively expensive and not widely available in most research laboratories. Another sterilization method is using potent chemicals, either gaseous (such as ozone and ethylene oxide) or liquid (such as ethanol, sodium hypochloride (bleach), formaldehyde, hydrogen peroxide, peracetic acid, and quaternary ammonium) [12, 13]. However, not all chemicals are effective or suitable for sterilizing tissue scaffolds.

*Address correspondence to this author at the 140 West 19th Avenue, Columbus OH 43210, USA; Tel: (614) 292-6611; E-mail: yang.15@osu.edu

${ }^{\#}$ Current address: Shire Human Genetic Therapies, 700 Main Street, Cambridge MA 02139, USA.
In this work, a novel chemical sterilization method using benzalkonium chloride, also known as BAC [14], was studied. BAC, a quaternary ammonium salt, is a wide-spectrum biocide that has also been used as a deodorant and sanitizer [15]. BAC can disrupt intermolecular interactions crucial to cellular membrane lipid bilayers, which can cause the leakage of cellular contents and interrupt the permeability control of the cells. BAC also can kill cells through DNA disruption [16]. Although not widely used in scaffold sterilization, it has found wide applications in water treatment, hospitals, hand sanitizers, pharmaceuticals [17 and references therein], dairy and food processing plants, swimming pools, the paper industry, poultry and animal husbandry, aquaculture, and the sugar industry. Furthermore, this rapid acting, water-soluble, and strong electrolyte is nontoxic, highly stable, biodegradable, and economical [18 and references therein].

Substantial research has been conducted on BAC, but never as a scaffold sterilization agent [19-21]. Imbert et al. (2003) applied benzalkonium chloride as the plastic treatment agent to control the adherence of Candida albicans on the surface [22]. However, they did not assess the biocidal activity of the BAC solution for sterilization of tissue engineering scaffolds. Additionally, they proposed that the contamination of medical prostheses can be avoided simply by controlling fungal adherence, such as the adherence of $C$. albicans.

The goal of this study was to evaluate the effectiveness and suitability of benzalkonium chloride as a sterilization agent for treating needle-punched nonwoven polyethylene terephthalate (PET) scaffolds and the cytotoxicity of BAC on astrocyte cell cultures. PET fibrous matrices are economical, chemically and thermally stable, highly porous and interconnected, and have been widely used for culturing various mammaliam cells [23, 24], including human trophoblast [24- 
26], osteosarcoma [27], murine embryonic stem cells [28], and astrocytes [29]. Astrocytes play a significant role in the central nervous system. It has been previously suggested that astrocytes cultured in PET scaffolds could provide a transplantable cell therapy platform for treating the Parkinson's disease [29]. In this work, long-term astrocyte cultures in PET scaffolds were demonstrated to confirm the suitability and effectiveness of the BAC sterilization method.

\section{MATERIALS AND METHODS}

\section{Materials}

Benzalkonium chloride (BAC) was purchased from Aldrich (Milwaukee, MI) and used as received. BAC solutions with various concentrations $(0.1 \mu / \mathrm{L}$ to $1 \mathrm{~g} / \mathrm{L})$ were prepared by dissolving the appropriate amounts of BAC in deionized (DI) water and then filtered with a $0.2-\mu \mathrm{m}$ filter before use. Needle-punched nonwoven polyethylene terephthalate (PET) fabrics (fiber diameter, $\sim 20 \mu \mathrm{m}$; fiber density, $1.35 \mathrm{~g} / \mathrm{cm}^{3}$ ) were used as cell culture scaffolds.

Electrospun polylactic acid (PLA) nanofibrous matrices were prepared by dissolving $4 \mathrm{wt} \%$ of lactide in a $2: 1 \mathrm{mix}-$ ture of dichloromethane and trifluoroacetic acid and stirring at room temp for approximately 4 hours until completely dissolved. The solution was then poured into a syringe with a blunt tip stainless steal needle and loaded into a syringe pump set to $16 \mathrm{~mL} / \mathrm{h}$. A high voltage power supply was set to $22 \mathrm{kV}$ and a deposition surface of aluminum foil was placed $20 \mathrm{~cm}$ from the needle tip. The resulting nanofibers have a diameter of approximately $600 \mathrm{~nm}$.

\section{Cell Cultures}

Human astrocytoma cells CCF-STTGI (ATCC: CRL 1718) were grown in Dulbelco's Modified Eagle Medium (DMEM) with high glucose, L-glutamine, $110 \mathrm{mg} / \mathrm{L}$ sodium pyruvate and pyridoxine hydrochloride (Caisson Laboratories, Inc.). Unless otherwise noted, DMEM was supplemented with $10 \%(\mathrm{v} / \mathrm{v})$ fetal bovine serum (Gibco) before use and the culture was incubated in a $5 \% \mathrm{CO}_{2}$ incubator at $37^{\circ} \mathrm{C}$. The cultures were maintained by changing the culture medium every three days and were subcultured whenever the cell density reached $90 \%$ confluence.

To demonstrate the effectiveness and suitability of BAC sterilization, PET scaffolds, after treated with $1 \mathrm{~g} / \mathrm{L}$ BAC for 2 minutes and washing with sterile deionized water, were seeded with astrocyte cells $\left(10^{5}\right.$ cells per well) and incubated for 13 days. The culture media were refreshed on day 8 . Positive controls were carried out by culturing the cells in PET scaffolds sterilized by autoclaving. Cell growth activity was followed by monitoring the concentrations of lactic acid and glucose in the culture media.

\section{BAC Sterilization of PET Scaffolds}

Fibrous PET scaffolds were used to assess the effectiveness of BAC as a sterilization agent. The PET scaffolds were cut into a disk shape $(1 \mathrm{~cm}$ diameter) and were placed into a 24-well tissue culture plate. One $\mathrm{mL}$ of $1 \mathrm{~g} / \mathrm{L} \mathrm{BAC}$ or sterile distilled water (negative control) was added to each well on the plate. After 1 minute, some of the BAC-treated scaffolds were washed with sterile distilled water to remove BAC. Then, $1 \mathrm{~mL}$ of Dulbelco's Modified Eagle Medium was added to each well and the plate was incubated at $37{ }^{\circ} \mathrm{C}$ overnight to observe the growth of possible contaminants. To assess the presence of microbial growth, the turbidity of the supernatant medium was analyzed by measuring the optical density at $600 \mathrm{~nm}$.

\section{The Toxicity Effect of BAC on Astrocyte Culture}

The cytotoxicity of BAC on astrocyte cell cultures was evaluated by assessing the metabolic activity of astrocytes at a wide range of BAC concentration levels from $0.1 \mu \mathrm{g} / \mathrm{L}$ to $100 \mathrm{mg} / \mathrm{L}$ with $10 \times$ increment. The experiment was carried out in a 24-well tissue culture plate. Each well containing one $\mathrm{mL}$ of DMEM and various amounts of BAC was inoculated with $10^{5}$ cells and incubated for 5 days. The metabolic activities of the cultures were monitored by analyzing the lactic acid and glucose concentrations in the culture media on daily basis. Briefly, $0.1 \mathrm{~mL}$ of the culture medium was taken from each well and then $0.1 \mathrm{~mL}$ of fresh medium was added to maintain a constant liquid volume in the well.

\section{BAC Sterilization of PLA Nanofibers}

Electrospun polylactic acid (PLA) nanofibers were used to evaluate possible effects of various sterilization methods on the nanostructures of the nanomaterials. The PLA nanofibers were either autoclaved at $121^{\circ} \mathrm{C}$ for 15 minutes, soaked in $70 \%(\mathrm{v} / \mathrm{v})$ ethanol for 1 hour, or treated with $1 \mathrm{~g} / \mathrm{L} \mathrm{BAC}$ for 2 minutes. The treated nanofibers were than air dried and observed under a scanning electron microscope (SEM) to study possible structural changes caused by these sterilization treatments.

\section{Analytical Methods}

The glucose and lactic acid concentrations in the culture media were monitored using a glucose analyzer (Yellow Spring Instruments, $\mathrm{OH})$. The media were centrifuged and the supernatant was then tested for glucose and lactic acid concentrations. The concentrations of the microorganisms in the culture media were quantified by measuring the optical density (OD) at $600 \mathrm{~nm}$ wavelength using a UV-vis spectrophotometer (Model 340, Sequoia-Turner).

\section{Statistical Analysis}

Unless otherwise noted, all experiments were triplicated $(\mathrm{n}=3)$ and representative data with statistical significance are reported. Numerical data were analyzed using standard analysis of variance (ANOVA) techniques (using JMP®); statistical significance was considered at $p<0.05$.

\section{RESULTS AND DISCUSSION}

\section{BAC Sterilization of PET Scaffolds}

The effectiveness of BAC as a sterilization agent for treating PET scaffolds was demonstrated in the experiments shown in Fig. (1A). After overnight incubation in DMEM, PET scaffolds treated by washing with filter-sterilized distilled water showed a significantly higher average optical density than the control ( $\mathrm{p}$-value $<0.04)$, indicating the presence of microbial contamination. About $80 \%$ contamination rate was observed with scaffolds not sterilized or treated with BAC. On the other hand, the average OD reading of the culture media containing washed PET scaffolds after BAC treatment was almost identical to that of the control ( $p$-value $=0.97$ ), implying no microbial contamination. The OD read- 
ings of the culture media containing BAC treated scaffolds (without washing) were slightly higher than that of the control ( $\mathrm{p}$-value $=0.86$ ), indicating possible interference of BAC with some medium components. These results confirmed that only one minute treatment with $1 \mathrm{~g} / \mathrm{L} \mathrm{BAC}$ solution was effective in achieving the sterility of the PET scaffolds.

The robustness and efficacy of BAC in killing potential contaminants was further studied with PET scaffolds deliberately contaminated with Bacillus $s p$. As shown in Fig. (1B), a short treatment of 2 minutes with $1 \mathrm{~g} / \mathrm{L}$ BAC was effective to kill the bacteria in the bacteria-soaked scaffolds, seen by the low OD reading (compared to the DI water treated scaffolds). The slightly higher OD reading compared to the control was attributed to the dead bacterial cells detached from the scaffolds.

\section{Cytotoxicity Effect of BAC}

Because of the presence of pores within the PET scaffolds, treating the scaffolds with $\mathrm{BAC}$ can also result in the accumulation of residual BAC inside the scaffolds. Although complete removal of this residual is almost impossible, properly washing the scaffolds with water can dilute the BAC concentration in the scaffolds. It is thus of interest to study the cytotoxicity effect of BAC at various concentration levels. In the experiment, cell metabolic activity, as indicated by changes in the lactic acid concentration in the media, were used to assess the cytotoxicity of BAC on astrocyte cultures. Previous study has established a strong correlation between lactic acid production and the number of viable cells in the culture medium [30]. Fig. (2A) shows the kinetics of lactic acid production in the astrocyte cultures. As can be seen in Fig. (2A), no significant lactic acid production was observed in the culture media containing $1 \mathrm{mg} / \mathrm{L}$ or a higher concentration of BAC (p-value $<0.0001$, compared to the control), suggesting that $1 \mathrm{mg} / \mathrm{L}$ was a detrimental concentration for astrocytes. On the other hand, at a BAC concentration of $100 \mathrm{ppb}$ or lower, the lactic acid production was comparable to that of the control (without BAC). It thus can be concluded that BAC at low concentrations $(<100 \mu \mathrm{g} / \mathrm{L})$ is

$\mathbf{A}$

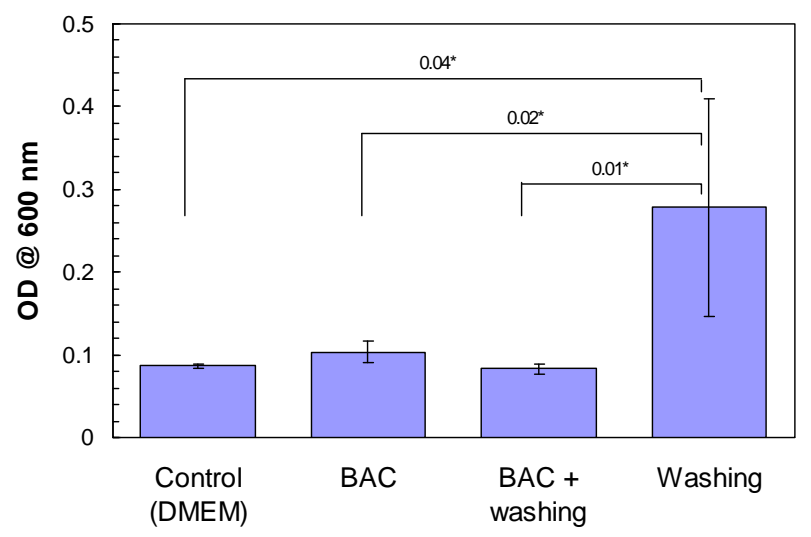

not toxic to cells. This finding is consistent with the study conducted by Deutchle et al. whose study concluded that BAC exhibited no cytotoxic effect at $20 \mathrm{mg} / \mathrm{L}$ [31]. Although BAC was shown to be toxic to cells from 50 to 100 $\mathrm{mg} / \mathrm{L}$, it lost its toxicity at the critical micelle concentration (CMC), which was found to be $200 \mathrm{mg} / \mathrm{L}$ [31]. It is unclear, however, why the micelle formation would diminish the toxicity level and how cells would respond to that. Similar finding with marine diatoms was also reported [32].

The presence of serum proteins and other serum components and ions in the culture medium can react and thus neutralize the BAC salt, resulting in the lack of observable toxicity on the astrocyte cells. To evaluate the possible effect of serum on the observed cytotoxicity level of BAC, similar experiments were conducted in serum-free media and the results are shown in Fig. (2B). As expected, the metabolic activity of astrocytes was lower in the absence of serum, indicated by the lower levels of lactic acid concentration in the medium. However, the presence of BAC at a low concentration between 0.1 and $100 \mu \mathrm{g} / \mathrm{L}$ did not significantly inhibit cell metabolism, although it did show a more notable negative effect on cell metabolic rate or lactic acid production rate in the serum-free media ( $\mathrm{p}$-value > 0.05). This result suggests that washing the scaffolds with sterile water after BAC sterilization is required in order to reduce the residual BAC concentration down to a non-toxic level.

It should be noted that Kummerer et al. have demonstrated that BAC is degradable after a period of time in solution [18]. Although BAC can potentially be toxic to cells [33], once degraded and neutralized, it has no toxic effect on cell culture, as shown by Garcia et al. (2002) working with myenteric neurons of Wistar rats [34].

\section{Astrocyte Cultures in BAC Sterilized PET Scaffolds}

The effectiveness of BAC sterilization followed with washing the scaffolds to eliminate the detrimental effect of residual BAC was assessed with astrocyte cultures in PET scaffolds. Fig. (3) shows the production of lactic acid in astrocyte cultures, indicating healthy cell growth of astrocytes

B

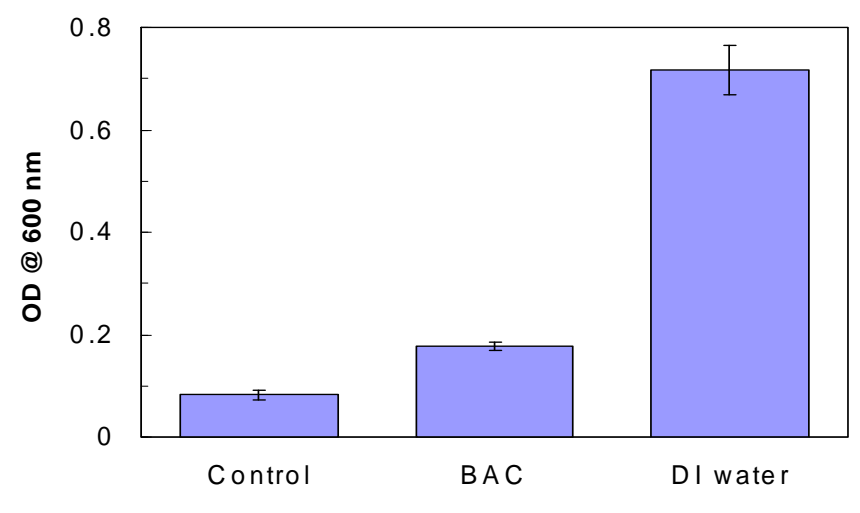

Fig. (1). The turbidity or optical density (OD) of DMEM after incubating with PET scaffolds treated with BAC, BAC + washing, or washing only (A) and with PET scaffolds presoaked in Bacillus subtilis suspension followed with treatment with $1 \mathrm{~g} / \mathrm{L}$ BAC for 2 minutes or washing with DI water (B). DMEM without the PET scaffold was used as the control. Note the higher optical density observed for DMEM with PET scaffolds treated with only washing suggested the presence of contaminating microorganisms. A p-value of $<0.05$ indicates a significant difference between the pair as indicated. Average values of triplicates are reported with error bars representing the standard deviation. 
A

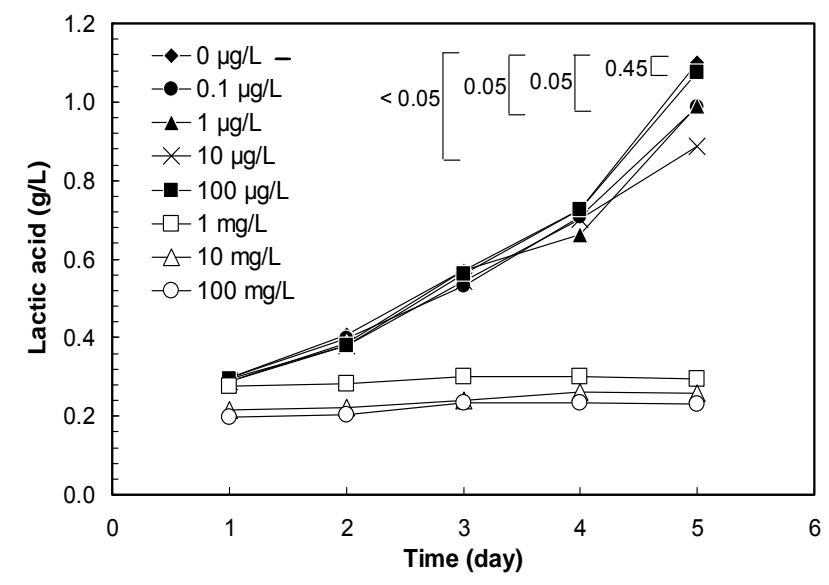

B

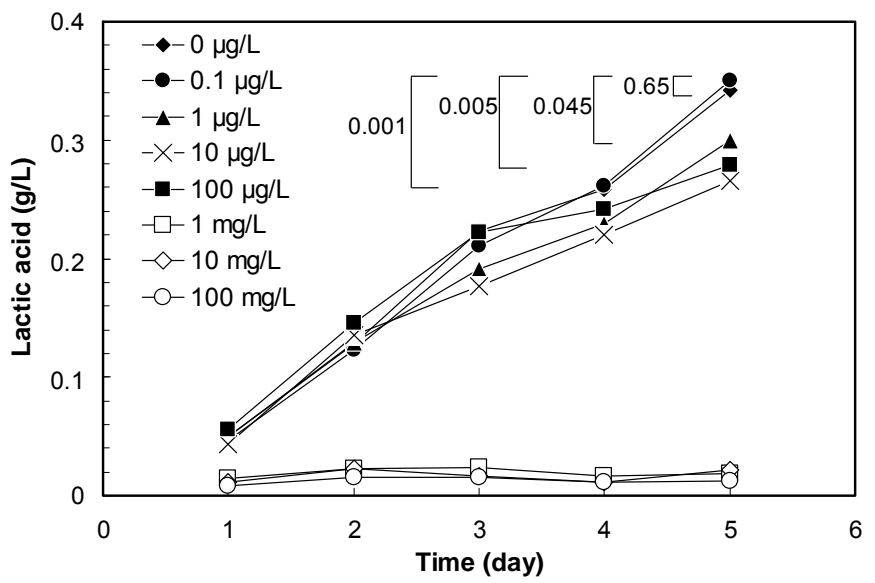

Fig. (2). Effects of BAC on metabolic activity of astrocytes grown in DMEM $+10 \%$ FBS (A) and serum free media (B). The effect on cell metabolism is inferred by the production of lactic acid in the culture media. Average values of triplicates are reported. No significant cell growth was observed in media containing $10^{3}, 10^{4}$ and $10^{5} \mu \mathrm{g} / \mathrm{L} \mathrm{BAC}$ (p-value $<0.0001$ ). A p-value of $<0.05$ indicates a significant effect of BAC on cell metabolism.

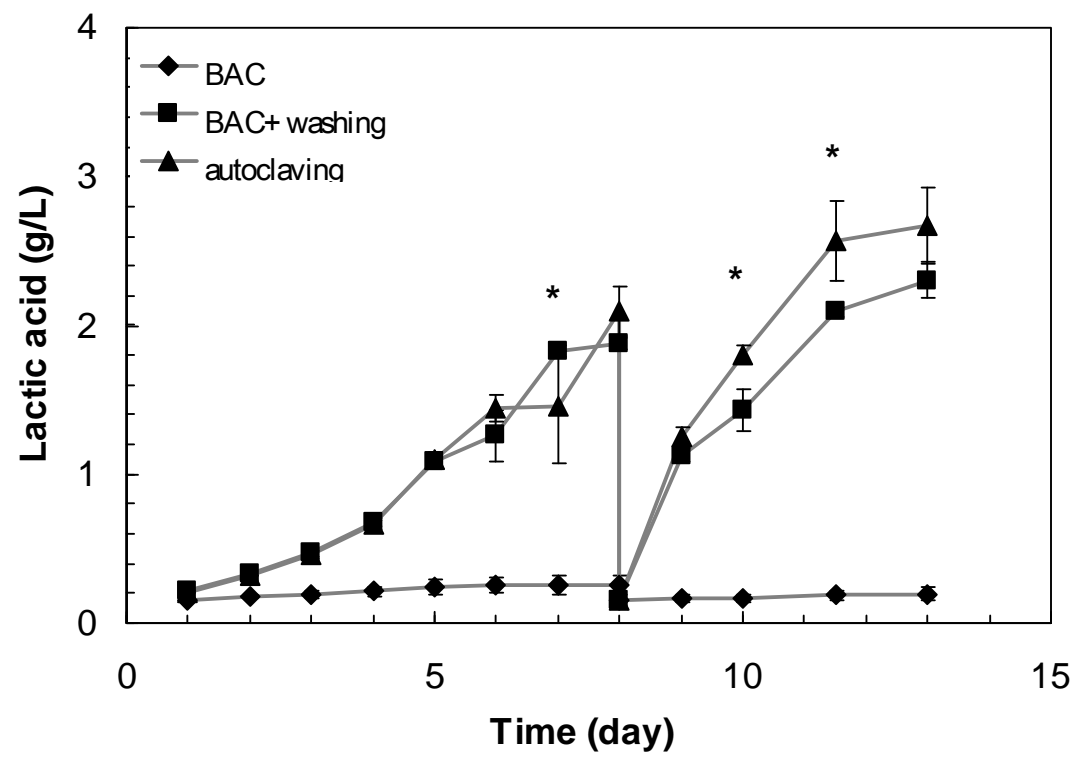

Fig. (3). Astrocyte cultures in PET scaffolds sterilized by different methods (BAC, BAC + washing, and autoclaving). Average values of triplicates are reported with error bars representing the standard deviation. On day 8, culture media were replaced with fresh media. There was no significant difference between treatments with autoclaving and BAC + washing. Asterisks indicate data points where the p-values are less than 0.05 .

in BAC-sterilized PET scaffolds. The lactic acid production kinetics of this culture was similar to that of control, which grown in autoclaved scaffolds ( $p$-value $>0.05$ ). Notable differences were found in only three time points: 6 days (pvalue $=0.046), 10$ days $(\mathrm{p}$-value $=0.028)$ and 11.5 days $(\mathrm{p}$ value $=0.046$ ), which are weak grounds for rejecting the null. It is noted that the production of lactic acid is strongly correlated to cell growth during the exponential growth phase. Therefore, it can be concluded that the growth of astrocyte on scaffolds sterilized by $1 \mathrm{~g} / \mathrm{L} \mathrm{BAC}$, followed by proper washing, is not significantly different from that on autoclaved scaffolds. On the other hand, no growth was observed on the BAC-treated scaffolds without washing, indicating that proper washing is required.

\section{Applications in Nanostructured Materials}

Recently, progress in the area of nanobiotechnology has provided numerous ways to produce nanotextured biomaterials. These polymeric nanostructured biomaterials can lose nanotopography when subjected to ethanol, gamma or heat sterilization [35-36]. On the other hand, sterilization using detergent can be harmful for cell growth. Sterilization time is another disadvantage of heat, ethanol or irradiation sterilization. Typical heat sterilization requires up to 30 minutes, whereas irradiation and ethanol sterilizations usually require several hours. In a recent study, it was also demonstrated that UV-ozone and ethylene oxide treatments damaged the sur- 

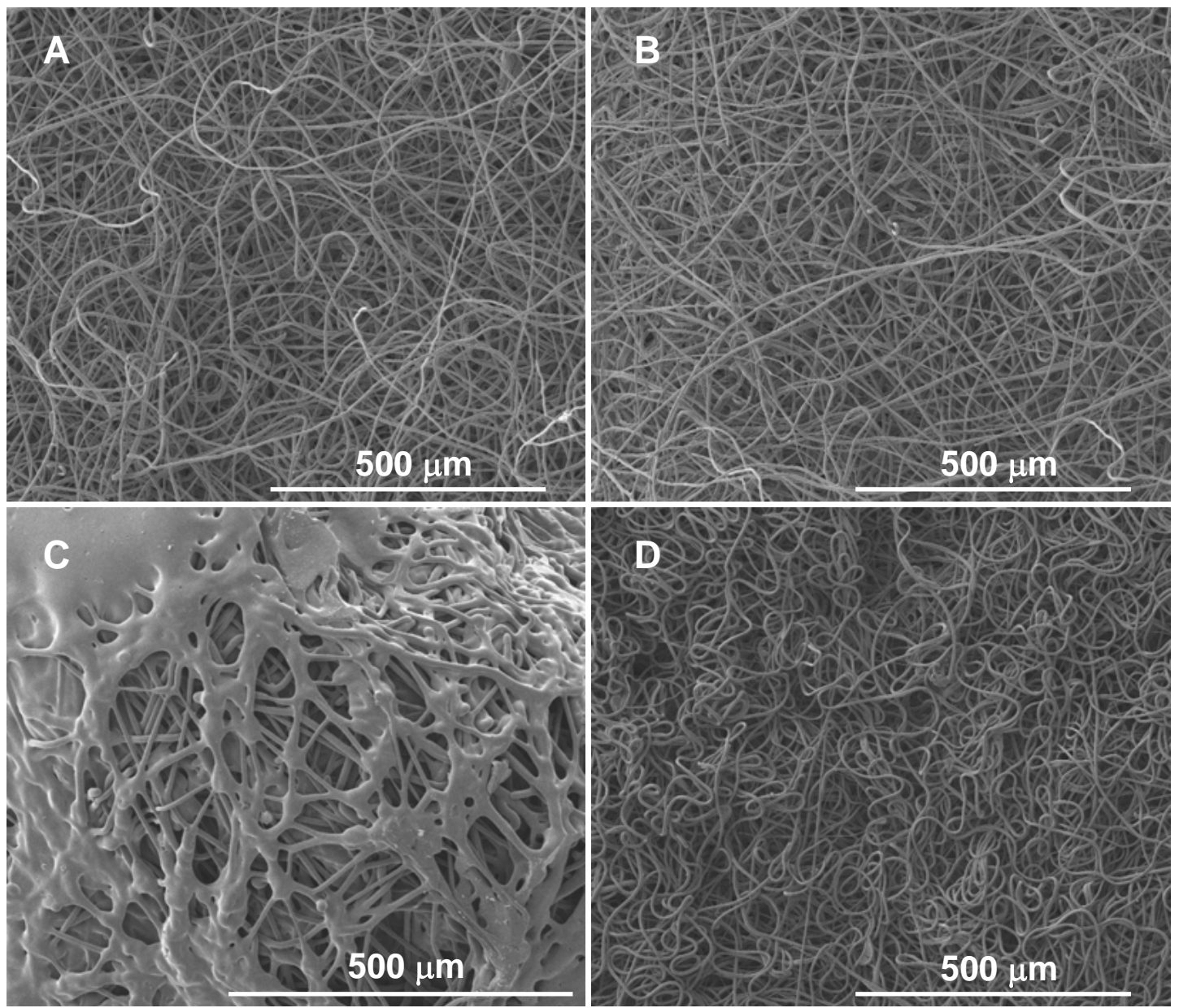

Fig. (4). Scanning electron micrographs of poly(lactic-acid) nanofibers. (A) Before treatment; (B) After treating with 1 g/L BAC; (C) After heat treatment; (D) After treating with 70\% (v/v) ethanol. Notice the structure rupture of heat-treated nanofibers $(\mathbf{C})$ and the altered structure of the nanofibers after ethanol treatment (D). The BAC treatment preserved the nanostructure of the nanofibers.

face topography of nanotextured surfaces and affected cell attachment and proliferation [37].

A faster, more reliable, and noninvasive sterilization method is preferred, and therefore, BAC sterilization was tested on mechanically delicate nanofibrous PLA to demonstrate its potential applications in this field. The microstructures of the PLA nanofibers before and after sterilization by various methods are shown in Fig. (4). Treatment with the BAC solution at $1 \mathrm{~g} / \mathrm{L}$ was demonstrated to be a rapid and non-invasive way to sterilize the nanofibers while preserving the nanostructures of the nanofibers (Fig. 4B). In contrast, polylactic acid nanofibers shrank and hardened, and their nanosized features were largely destroyed by heat treatment (Fig. 4C), whereas ethanol treatment also altered the microscopic structures of the nanofibers (Fig. 4D). Clearly, BAC sterilization is a conducive method for treating nanomaterials without altering their structural features.

\section{CONCLUSION}

The sterilization of biomaterials, either natural or synthetic, is important in tissue engineering and cell cultures. The current sterilization techniques are either impractical or harmful, if not ineffective, to be used for tissue scaffolds. Aside from being time consuming, sterilization using $70 \%$ ethanol is not effective. On the other hand, polymeric nanostructured biomaterials can lose their nanotopography when subjected to ethanol, UV, or heat sterilization. Sterilization using detergents is harmful for cell growth. In addition to the relatively short treatment time compared to those of other sterilization methods, BAC sterilization does not disrupt the textures of nanostructured substrates. This study demonstrated a fast, potent, and effective way to sterilize fibrous PET scaffolds for tissue engineering applications. Although BAC was assessed as a cost-effective and time-saving alternative for sterilization in this work, further studies need to be conducted with other mammalian cells that are more commonly used in tissue engineering in order to validate the general applicability of this BAC sterilization method.

\section{ACKNOWLEDGEMENTS}

This work was partially supported by the University Presidential Fellowship and the Alumni Grants for Graduate Research and Scholarship (AGGRS) Program of The Ohio State University.

\section{REFERENCES}

[1] Ma PX. Scaffolds for tissue fabrication. Mater Today 2004; 7(5): $30-40$. 
[2] Wang G, Zhang W, Corey J, David F, Lee E, Avinoam K. Modified Celligen-packed bed bioreactors for hybridoma cell culture. Cytotechnology 1992; 9: 41-9.

[3] Chen C, Huang YL, Yang ST. A fibrous-bed bioreactor for continuous production of developmental endothelial locus-1 by osteosarcoma cells. J Biotechnol 2002; 97: 23-39.

[4] Chiou TW, Murakami S, Wang DIC, Wu WT. A fiber-bed bioreactor for anchorage-dependent animal cell cultures: part I. Bioreactor design and operations. Biotechnol Bioeng 1991; 37: 755-61.

[5] Highfill JG, Haley SD, Kompala DS. Large-scale production of murine bone marrow cells in an airlift packed bed bioreactor. Biotechnol Bioeng 1996; 50: 514-20.

[6] Junker BH, Chiou T, Wang DIC, Buckland BC. Cultivation of virus antigen in fibroblast cells using a glass fiber bed reactor. Biotechnol Bioeng 1993; 42: 635-42.

[7] Ma T, Li Y, Kniss DA, Yang ST. Tissue engineering human placenta trophoblast cells in 3-D fibrous matrix: spatial effects on cell proliferation and function. Biotechnol Prog 1999; 15: 715-24.

[8] Ma T, Li Y, Yang ST, Kniss DA. Effects of pore size in 3-D fibrous matrix on human trophoblast tissue development. Biotechnol Bioeng 2000; 70: 606-18.

[9] Motobu M, Matsuo S, Wang P-C, Kataoka H, Matsumura M. High renin productivity of $\mathrm{rCHO}$ cells cultivated in radial-flow nonwoven fabric mat packed-bed reactor with increasing circulating flow rate. J Ferment Bioeng 1997; 83: 443-450.

[10] Murakami S, Chiou TW, Wang DIC. A fiber-bed bioreactor for anchorage-dependent animal cell cultures: part II. Scale-up potential. Biotechnol Bioeng 1991; 37: 762-769.

[11] Perry SD, Wang DIC. Fiber bed reactor design for animal cell culture. Biotechnol Bioeng 1989; 34: 1-9.

[12] Pernak J, Kalewska J, Ksycinska H, Cybulski J. Synthesis and antimicrobial activities of some pyridium salts with alkoxymethyl hydrophobic group. Eur J Med Chem 2001; 36: 899-907.

[13] Turkun M, Ozata F, Uzer S, Ates M. Antimicrobial substantivity of cavity disinfectants. Gen Dent 2005; 53(3): 182-6.

[14] Thomas L, Russell AD, Maillard JY. Antimicrobial activity of chlorhexidine diacetate and benzalkonium chloride against Pseudomonas aeruginosa and its response to biocide residue. J Appl Microbiol 2005; 98: 533-43.

[15] Dyer DL, Kenneth BG, Peter SW. Testing a new alcohol-free hand sanitizer to combat infection. AORN J 1998; 68(2): 239-51.

[16] Sanchez-Fortun S, Lorente MT, Castano A. Genotoxic effects of selected biocides on RTG-2 fish cells by means of a modified Fast Micromethod Assay. Aqua Toxic 2005; 73: 55-64.

[17] Xue Y, Hieda Y, Kimura K, Takayama K, Fujihara J, Tsujino Y. Kinetic characteristics and toxic effects of benzalkonium chloride following intravascular and oral administration in rats. J Chromatogr B Analyt Technol Biomed Life Sci 2004; 881: 53-8.

[18] Kummerer K, Al-Ahmed A, Henninger A. Use of chemotaxonomy to study the influence of benzalkonium chloride on bacterial populations in biodegradable testing. Acta Hydrochim Hydrobiol 2002; 30(4): 171-8.

[19] McFadden JP, Holloway DB, Whittle EG, Basketter DA. Benzalkonium chloride neutralizes the irritant effect of sodium dodecyl sulfate. Contact Dermatitis 2000; 43: 264-66.

[20] Basketter DA, Marriott M, Gilmour NJ, White IR. Strong irritants masquerading as skin allergens: the case of benzalkonium chloride. Contact Dermatitis 2004; 50: 213-17.
[21] Larsen ST, Hansen R, Poulsen OM, Nielsen GD. Adjuvant effect of benzalkonium chloride on the allergen-specific $\operatorname{IgE}, \operatorname{IgG} 1$ and IgG2a antibody formation in BALB/cJ mice. Pharmacol Toxicol 2004; 95: 94-6.

[22] Imbert C, Lassy E, Daniault G, Jacquemin JL, Rodier MH. Treatment of plastic and extracellular matrix components with chlorhexidine or benzalkonium chloride: effect on Candida albicans adherence capacity in vitro. J Antimicrob Chemother 2003; 51: 2817.

[23] Ma T, Li Y, Kniss DA, Yang ST. Tissue engineering human placenta trophoblast cells in 3-D fibrous matrix: spatial effects on cell proliferation and function. Biotechnol Prog 1999; 15: 715-24.

[24] Li Y, Kniss DA, Lasky LC, Yang ST. Culturing and differentiation of murine embryonic stem cells in a three-dimensional fibrous matrix. Cytotechnology 2001; 41(1): 23-35.

[25] Li Y, Yang ST. Effects of three-dimensional scaffolds on cell organization and tissue development. Biotechnol Bioprocess Eng 2001; 6: 311-25.

[26] Ma T, Li Y, Yang ST, Kniss DA. Effects of pore size in 3-D fibrous matrix on human trophoblast tissue development. Biotechnol Bioeng 2000; 70: 606-18.

[27] Chen C, Chen K, and Yang ST. Effects of 3D culturing on osteosarcoma cells grown in a fibrous matrix: Analyses of cell morphology, cell cycle and apoptosis. Biotechnol Prog 1999; 19: 157482.

[28] Ouyang A, Ng R, Yang ST. Long-term culturing of undifferentiated embryonic stem cells in conditioned media and threedimensional fibrous matrices without ECM coating. Stem Cell 2007; 25(2): 447-54.

[29] Basu S, Yang ST. Astrocyte growth and glial cell line-derived neurotrophic factor secretion in three-dimensional polyethylene terephthalate fibrous matrices. Tissue Eng 2005; 11(5/6): 940-52.

[30] Sun XM, Zhang YX. Estimation of Chinese hamster ovary cell density in packed-bed bioreactor by lactate production rate. Biotech Let 2003; 25: 853-7.

[31] Deutchle T, Porkert U, Reiter R, Keck T, Riechelmann H. In vitro genotoxicity and cytotoxicity of benzalkonium chloride. Toxicol In Vitro 2006; 20: 1472-7.

[32] Beveridge CM, Parr ACS, Smith J, Kerr A, Cowling MJ, Hodgkiess $T$. The effect of benzalkonium chloride concentration on nine species of marine diatom. Environ Pollut 1998; 103: 31-6.

[33] Acosta-Gio E, Herrero-Farias A, Mata-Portuguez VH. Benzalkonium chloride is unacceptable to sterilize or disinfect medical or dental instrument. Salud Publica Mexico 2001; 43(6): 1-4.

[34] Garcia SB, Demarzo MMP, Vinhadeli WS, et al. No reduction with aging of the number of myenteric neurons in benzalkonium treated rats. Neurosci Lett 2002; 331: 66-8.

[35] Nuutinen JP, Clerc C, Virta T, Tormala P. Effect of gamma, ethylene oxide, electron beam, and plasma sterilization on the behaviour of SR-PLLA fibres in vitro. J Biomater Sci Polymer Ed 2002; 13(12): 1325-36.

[36] Vastel L, Meunier A, Siney H, Sedel L, Courpied JP. Effect of different sterilization processing methods on the mechanical properties of human cancellous bone autographs. Biomaterials 2004; 25: 2105-10.

[37] Andrews KD, Hunt JA, Black RA. Effects of sterilization method on surface topography and in-vitro cell behavior of electrostatically spun scaffolds. Biomaterials 2007; 28: 1014-26.

(C) Ng et al.; Licensee Bentham Open.

This is an open access article licensed under the terms of the Creative Commons Attribution Non-Commercial License (http://creativecommons.org/licenses/by-nc/3.0/) which permits unrestricted, non-commercial use, distribution and reproduction in any medium, provided the work is properly cited. 